\title{
A Importância dos Fundamentos nos Ratings Soberanos Brasileiros, $1994-2002$
}

Rosemarie Bröker Bone*

Resumo: As crises financeiras internacionais da década de 90 aumentaram as dúvidas sobre a validade dos ratings soberanos. 0 presente trabalho tem dois objetivos. 0 primeiro identifica quais fundamentos explicam os ratings soberanos brasileiros, de dezembro de 1994 a dezembro de 2002, usando o modelo ordered logit. 0 segundo investiga o impacto dos fundamentose ratings nos spreads de dívida soberana. No primeiro caso, os resultados sugerem que a Dívida Externa sobre as Exportações, Dívida Líquida do Setor Público (em \%PIB), Necessidade de Financiamento do Setor Público (em \%PIB) e TransaçõesCorrentes (em \%PIB) são relevantes para explicar os ratings. No segundo caso, as variáveis relevantes foram a Taxa de Inflação (IPC) e, de novo, a Dívida Líquida do Setor Público (em \%PIB), N ecessidade de F inanciamento do Setor Público (em \%PIB) e Transações Correntes (em \%PIB). Em função dos resultados, pode-se afirmar que as finanças públicas são importantes na determinação dos ratings e retornos dos títulossoberanos. Finalmente, é importante destacar que quando os fundamentos são incluídos, o rating perde significância na explicação das variações do spread.

Palavras-chave: Rating Soberano, Fundamentos, Spread Brasil.

Abstract: The international financial crises of the 1990's raised doubts about the validity of sovereign ratings. This article has two goals. First, it aims to identify which fundamentals explain sovereign ratings for Brazil, from December 1994 to December 2002, using an ordered logit model. Second, investigate the impact of the fundamentals and ratings on sovereign debt spreads. In the first case, the results suggest that Foreign Debt as share of exports, Public Sector debt and deficit measures and Current account balance, all as share of GNP, are relevant to explain the ratings. In the second case, the relevant variables were the inflation rate and, again, Public Sector debt and deficit measures and Current account balance. O ne can conclude that public finances are an important determinant of sovereign ratings. Finally, hand, it is important to note that, once fundamentals are included, the rating itself does not significantly explain spread variations.

Keyw ords: Sovereign Rating, Fundamentals, Brazil Spread.

J EL Classification: E44 - Financial Markets and the Macroeconomy

\footnotetext{
Professora do Departamento de Engenharia Industrial/Escola Politécnica/UFRJ e Doutora em Economia pelo Instituto de Economia/UFRJ. E-mail: rosebone@terra.com.br.
} 


\section{Introdução}

A década de 90 foi marcada por importantes crises financeiras internacionais e pelo começo da demanda por ratings de tomadores de recursos - emitentes de títulos de dívida, principalmente nos países em desenvolvimento - ou emergentes. Contudo, essa combinação não foi vantajosa para o mercado, dado que os ratings não conseguiram antecipar as crises, impedindo os analistas de mercado de criar mecanismos de minimização de perdas nos portfólios.

Em função dessas perdas, os analistas de mercado acreditam que as agências além de não anteciparem as crises, também as alongaram, por meio de fortes downgrades e da permanência de classificações speculative grades, quando a situação já se encontrava controlada. Esses fatos aumentaram a certeza de que existe uma total desconexão entre o desempenho das variáveis-base (fundamentos), a frequência dos ratings e a precisão da nota. Também, que as crises de 1997 e 1998 foram o resultado de uma avaliação superficial do desempenho econômico-financeiro dos emitentes de títulos de dívida, que resultaram em ratings irreais.

Por outro lado, as agências de rating ${ }^{1}$ se defendem afirmando que esses emitentes precisam ter bons resultados e priorizar a transparência informacional, para obterem boas notas. Quando são "governo", as rubricas se referem aos fundamentos, mais fatores políticos (FMI, 1999b, p. 111). Neste caso, as agências apontam para a existência de fortes dificuldades de mensuração dos ratings de títulos soberanos emitidos pelo governo federal - em função da presença de forte componente político nas decisões econômicas e a alta da vulnerabilidade do país frente às crises externas, em função do grau de contágio.

A despeito dos conflitos existentes entre os analistas de mercado e as agências de rating, este mecanismo tem se tornado cada vez mais indispensável para os poupadores e tomadores de recursos. Para os poupadores, como fonte informacional adicional; para os tomadores, como um meio de expor a qualidade dos emissores de títulos de dívida.

O Brasil está totalmente inserido neste contexto, na medida em que necessita de fluxos de capitais externos para equilibrar o Balanço de Pagamentos e para os Investimentos Estrangeiros Diretos [IED]. Apesar da relativa estabilidade de preços, salários e câmbio, ${ }^{2}$ desde

\footnotetext{
As preocupações e os questionamentos realizados pelas agências de ratings podem ser endereçados a uma indústria informacional caracterizada por um duopólio de duas grandes empresas, a Standard \& Poor's e Moody's, que detêm juntas $80 \%$ das classificações de risco de soberanos (AFONSO, 2002).

2 Em janeiro de 1999, o câmbio administrado em vigor desde a implantação do Plano Real foi substituído pelo flutuante.
} 
julho de 1994, o país é acompanhado por uma fragilidade preocupante quanto à captação desses recursos, principalmente nas últimas crises financeiras externas (Ásia/97, Rússia e recapitalização do LTCM/98). A substituição do câmbio fixo pelo flutuante, em janeiro de 1999, foi fruto dessa fragilidade. Com o objetivo de minimizar os efeitos perversos de crises futuras, muitas iniciativas vêm sendo tomadas por parte do governo, visando diminuir os impactos sobre a economia interna e sobre suas relações internacionais. Entre as principais medidas, estão a disponibilização de informações ao mercado sobre a capacidade de pagamento das dívidas soberanas em moeda local e estrangeira de curto e longo prazos e o constante esforço em melhorar o desempenho dos indicadores macroeconômicos - fundamentos. Essas medidas refletem a crescente importância dos fundamentos nas avaliações dos analistas de mercado, uma vez que mudanças de tendência alteram o ânimo do mercado e geram variações abruptas do spread soberano.

Nesse sentido, o presente trabalho tem preocupação similar a de outros pesquisadores pós crise de 1997. No Brasil, os downgrades dos ratings soberanos ocorridos em 1999, após a mudança cambial, foram tidos como desnecessários, por não espelharem os fundamentos, e os upgrades posteriores chegaram quando a situação já estava, há muitos meses, controlada. Paralelamente a estes problemas, as oscilações do spread soberano foram excessivas, em virtude das incertezas políticas e dos descompassos do mercado financeiro internacional. Todavia, as análises apresentadas no debate político e econômico não foram acompanhadas de estudos rigorosos no Brasil.

O objetivo do trabalho é identificar quais fundamentos determinam os ratings soberanos brasileiros, usando os ratings emitidos pela agência Standard \& Poor's. ${ }^{3}$ Além disso, verificar o comportamento do spread soberano em resposta às reclassificações dos ratings soberanos brasileiros (downgrade/upgrade e mudanças de outlook) e as variações nos fundamentos.

O país possui ratings para os títulos emitidos em moeda local e estrangeira de curto e longo prazos, mas optou-se pelo rating dos títulos em moeda estrangeira de longo prazo, ao contemplar um período mais longo em relação aos demais - início em dezembro de 1994. A transformação dos ratings em números é similar às metodologias utilizadas por Mulder e Perelli (2001), Reinhart (2001) e de Bloomberg L.P.(2003). O método usado para a estimação é conhecido como ordered logit. Esse método tem como principal característica

\footnotetext{
3 A Standard \& Poor's emite ratings soberanos para os títulos brasileiros em moeda estrangeira de longo prazo, desde 1994, enquanto que a Moody's desde 1996, por isso a escolha da primeira.
} 
a existência de uma variável dependente ordinal discreta e é o mais recomendado, embora pouco usado, para a análise de ratings.

A escolha dos ratings soberanos se deve à importância da dívida emitida pelo Governo Federal para o mercado financeiro local e internacional e à repercussão em nível global, no caso de risco de default.

Os fundamentos mais repetidamente citados pelas agências de rating como determinantes dos ratings soberanos são: renda per capita, taxa de crescimento do PIB real, taxa de inflação (IPC), balanço fiscal (necessidade de financiamento do setor público (em \% PIB), balanço externo (transações correntes (em \%PIB), relação dívida externa/exportações, desenvolvimento econômico (conforme metodologia adotada pelo Fundo Monetário Internacional - $\mathrm{FMI}^{4}$ ) e história de default desde 1970. Como parte dos fundamentos, considerou-se a variável dívida líquida do setor público total (em \% PIB), uma vez que recentemente tem sido alvo de atenção dos analistas de mercado e incorporada às análises das agências de rating

0 estudo do spread soberano, num segundo momento, tem como propósito verificar se o rating soberano adiciona informações ao mercado além das contidas nos fundamentos.

Visando alcançar o objetivo, o trabalho será dividido em quatro seções além da introdução: 1) literatura; 2) descrição dos fundamentos dos ratings e dos spreads soberanos; 3) metodologia utilizada para a estimação; 4) análise dos resultados; 5) considerações finais.

\section{Literatura}

As análises dos ratings soberanos e da sua relação com o comportamento dos fundamentos e do spread soberano buscam entender a lógica das classificações de risco desenvolvidas pelas agências de rating e o grau de sabedoria do mercado em desmitificar esse processo.

Inúmeros trabalhos foram realizados ao longo dos últimos anos, sendo o artigo de Cantor e Packer (1996) aquele que abriu caminho para os demais. Os autores analisaram uma amostra de 49 países, divididos em industrializados e não industrializados, conforme o critério do Fundo Monetário Internacional - FMI - tendo como principais variáveis de análise os ratings e spreads soberanos emitidos em 29 de setembro de 1995. O objetivo principal para esses autores foi verificar a importância dos fundamentos sobre a média dos ratings soberanos e esses, por sua vez, sobre a média do spread soberano. Em outras palavras, saber se as informações contidas nos fundamentos

\footnotetext{
4 O FMI considera os países como industrializados ou não industrializados. (FMI, 1999a).
} 
são contempladas também nos ratings soberanos. As variáveis analisadas seguiram a metodologia das agências Standard \& Poor's e Moody's, quais sejam: renda per capita, crescimento do PIB, taxa de inflação, balanço fiscal, balanço externo, dívida externa, desenvolvimento econômico e história de default. As variáveis significativas em relação à média dos ratings soberanos foram: renda per capita, crescimento do PIB, taxa de inflação, dívida externa, indicador do desenvolvimento econômico e indicador para a história de default. Já em relação à influência dos ratings soberanos e fundamentos sobre 0 spread soberano, as variáveis significantes foram: o rating soberano médio, dívida externa, indicador de desenvolvimento e indicador para a história de default. 0 método de estimação usado foi o de Mínimos Quadrados Ordinários - MQO - apesar das várias tentativas, sem sucesso, de aplicação do Método Ordered Probit, apontado como sendo 0 melhor. ${ }^{5}$ Dos resultados obtidos, tiraram algumas conclusões importantes, sendo a principal o fato de que "(...) os ratings sumarizam e suplementam as informações contidas nos indicadores macroeconômicos e são fortemente correlacionados com os spreads. Por isso, pode-se dizer que as (...) informações disponíveis publicamente pelas agências de rating e pelos participantes de mercado são similares" (CANTOR; PACKER, 1996, p. 49).

Buscando verificar a abrangência dessas conclusões para os mais variados casos, novos trabalhos surgiram após 1996, principalmente após as crises da Ásia e da Rússia. Os Quadros 1 e 2 procuram resumir os principais trabalhos realizados desde então. 0 estudo dos ratings soberanos se encontram no Quadro 1 e, dos spreads soberanos, no Quadro 2. Os dados disponíveis nos quadros a seguir procuram descrever os trabalhos salientando os autores (data), objetivo, amostra, método de estimação, variável dependente (1) e independentes (2) e conclusões. Aqueles trabalhos que contemplam os objetivos principal e secundário foram subdivididos para uma melhor descrição.

Como se pode verificar nos Quadros 1 e 2, os autores que seguiram o trabalho de Cantor e Packer (1996) incluíram outras variáveis, além dos fundamentos apontados pelas agências de classificação, como determinantes dos ratings soberanos. 0 objetivo foi identificar as variáveis que melhor explicam tanto o comportamento dos ratings soberanos como dos spreads soberanos.

Uma síntese do Quadro 1 possibilita identificar as variáveis mais significativas no comportamento dos ratings soberanos emitidos pelas agências de ratings. As variáveis são: taxa de crescimento do PIB real, taxa de inflação, balanço do governo central/PIB, renegociação

5 Cantor \& Packer (1996) argumentam que outros estudos tiveram resultados similares entre o ordered probit e MQO com amostras grandes. 
da dívida com o FMI, dívida total/exportações e dívida externa/PIB. Percebe-se que as contas do governo federal, bem como a performance econômica interna, possui importância determinante nos ratings soberanos.

Monfort e Mulder (2000) acreditam ser as novas informações sobre os fundamentos o impulso para a mudança nos ratings soberanos. O u seja, a revisão somente ocorre a partir de um fato novo e/ ou pequenas mudanças nos fundamentos, pouco influenciando as agências para uma reclassificação. Isso permite afirmar que são as mudanças de tendência que levam aos upgrades ou downgrades dos ratings e não alterações transitórias.

Como os ratings podem mudar em resposta a mudanças nas variáveis econômicas e políticas, Haque, Mark e Mathieson (1998) concluíram que as variáveis políticas estão inseridas no comportamento dos fundamentos, ou seja, nas oscilações ocorridas nas variáveis econômicas. Neste caso, a inclusão de eventos políticos nos modelos torna-se desnecessária.

Nos trabalhos com relação aos spreads soberanos (Quadro 2), as principais conclusões foram:

(a) somente uma fração dos fundamentos explica o comportamento dos spreads soberanos (EICHENGREEN; MODY, 1998), o que suscitou a inclusão de outras variáveis julgadas como importantes, por exemplo, preço do petróleo, crises da década de 90, durations, renegociação da dívida com o FMI etc.;

(b) a taxa de juros do Tesouro Americano de curto prazo (3 meses) e os spreads soberanos, especificamente, apresentam correlação positiva. Uma subida da taxa de juros repercute fortemente sobre os países emergentes, fazendo com que o spread soberano aumente, visando a manutenção dos investidores nos títulos locais (KAMINSKY; SCHMUKLER, 2001);

(c) os ratings e spreads soberanos são influenciados pelos mesmos fundamentos. Os ratings soberanos serão uma fonte informacional adicional somente se o mercado não puder antecipar os fatos novos (REISEN; VON MALTZAN, 1999);

(d) os ratings podem causar a saída de capitais dos países emergentes (LARRAÍN; REISEN; VON MALTZAN, 1997).

Este trabalho tem preocupação similar ao de muitos pesquisadores apontados anteriormente, uma vez que os downgrades dos ratings soberanos brasileiros ocorridos em 1999, após a mudança cambial no Brasil, foram tidos como desnecessários, pois não espeIharam os fundamentos e os upgrades posteriores chegaram atrasados. Esse perfil conservador das agências de rating é apontado por Ferri et al. (1999) como um processo de reconquista da reputação abalada com os erros ocorridos no período pré-crise da Ásia. 
Quadro 1 - Principais trabalhos sobre o comportamento dos ratings soberanos

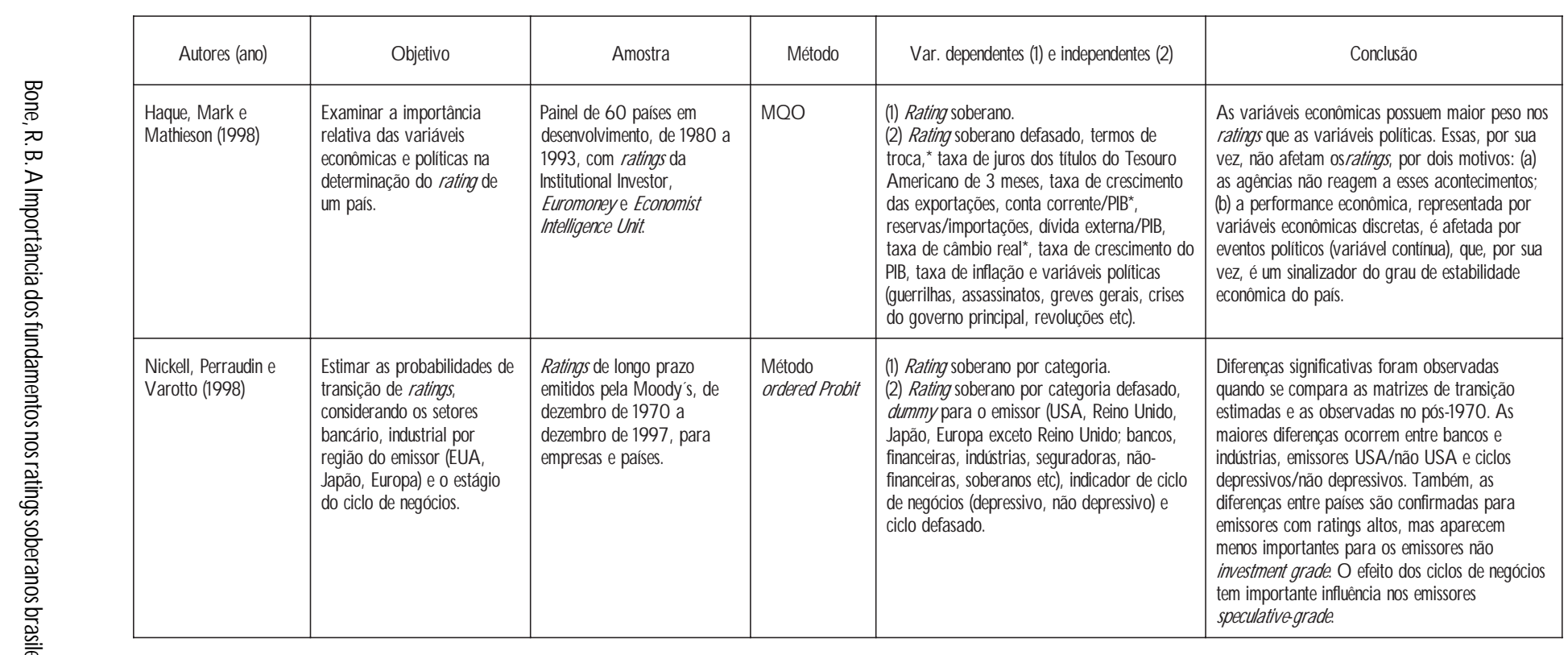




\begin{tabular}{|c|c|c|c|}
\hline$\frac{8}{8}$ & 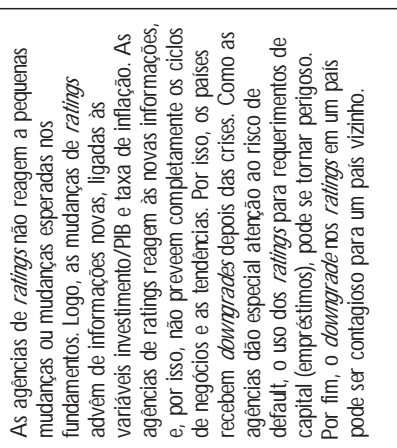 & 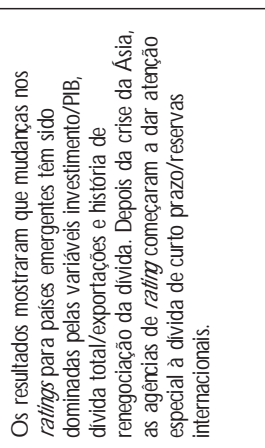 & 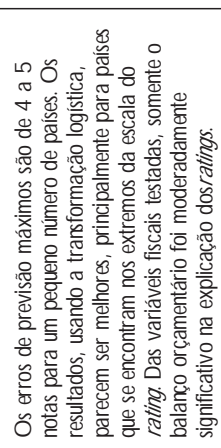 \\
\hline 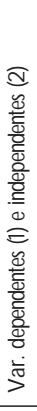 & 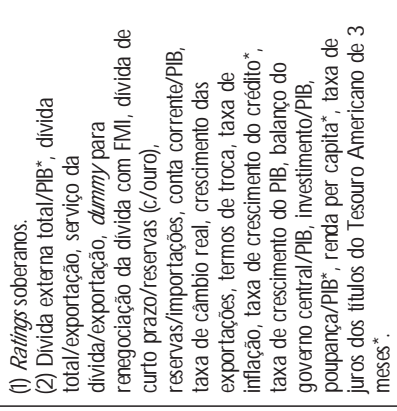 & 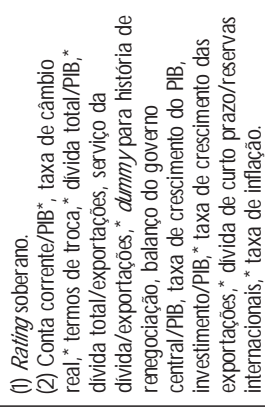 & 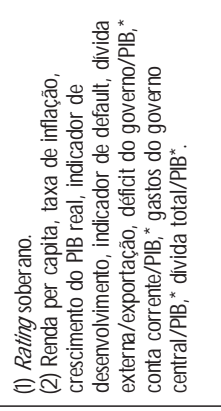 \\
\hline ह & 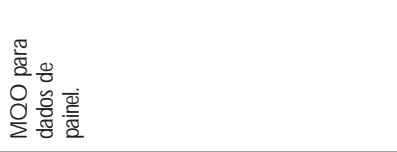 & 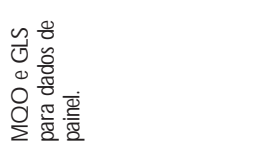 & 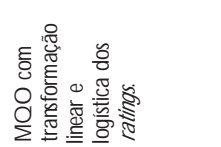 \\
\hline$\frac{8}{8}$ & 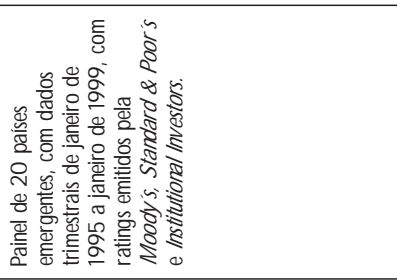 & 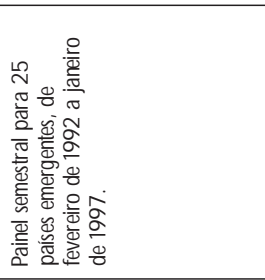 & 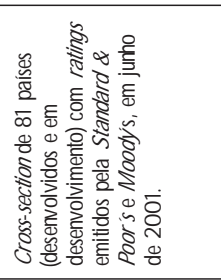 \\
\hline$\frac{8}{8}$ & 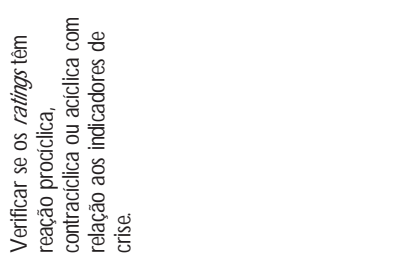 & 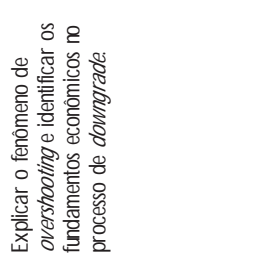 & 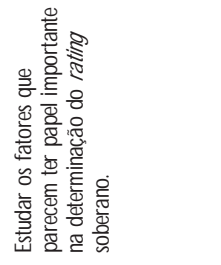 \\
\hline 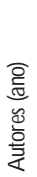 & 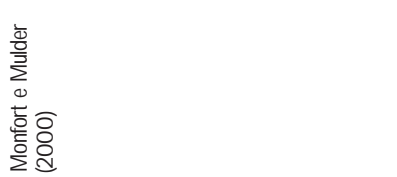 & 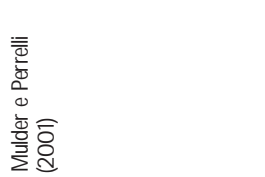 & 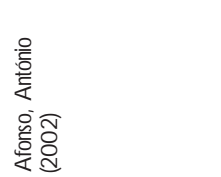 \\
\hline
\end{tabular}




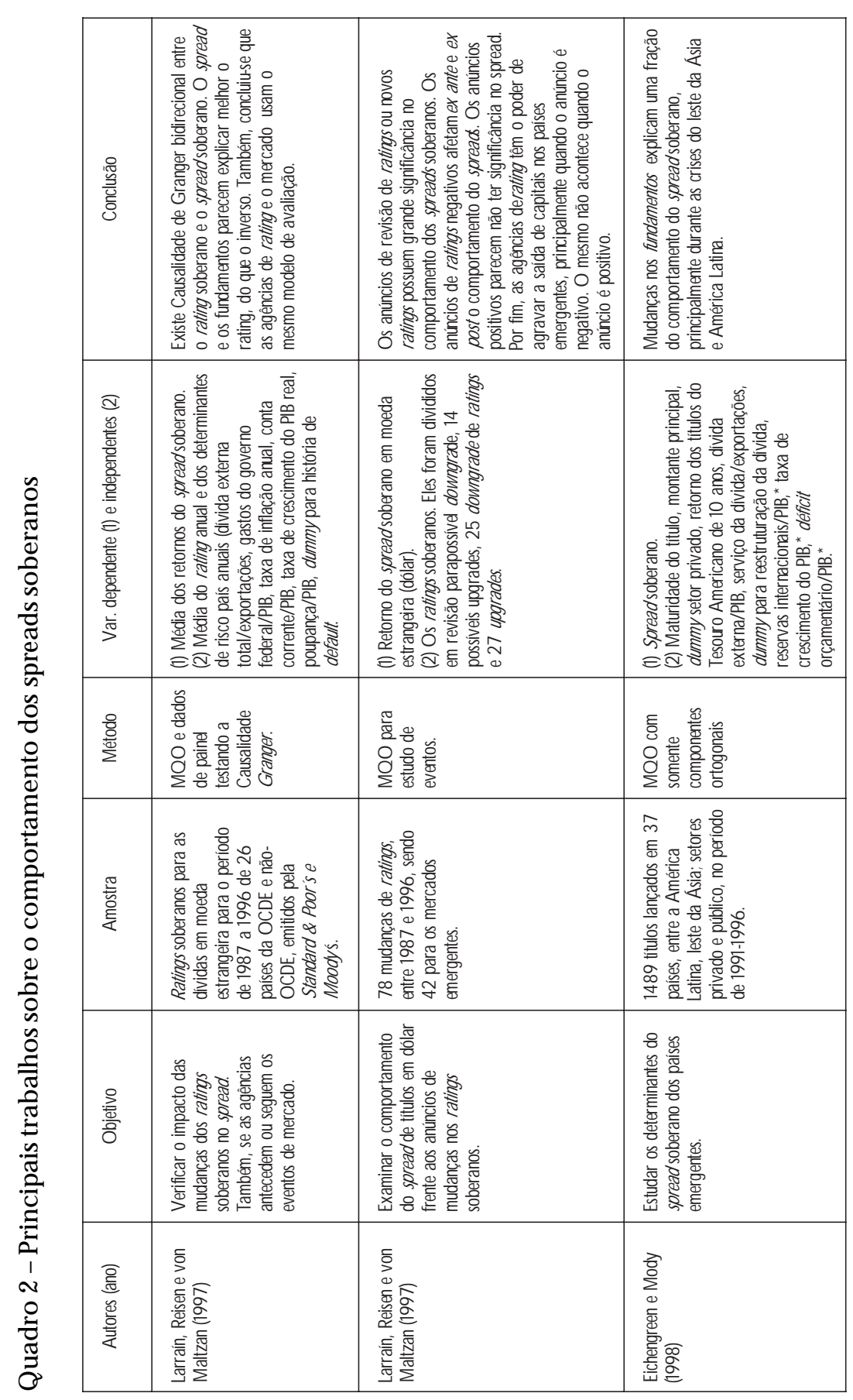

Bone, R. B. A Importância dosfundamentos nos ratingssoberanos brasileiros... 


\begin{tabular}{|c|c|c|c|}
\hline ही & 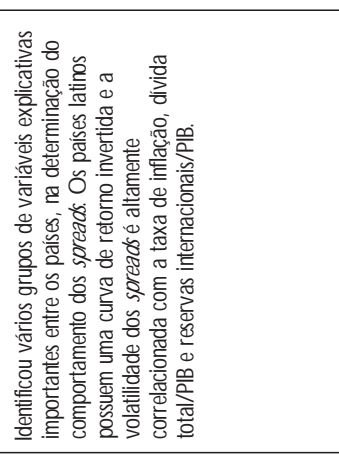 & 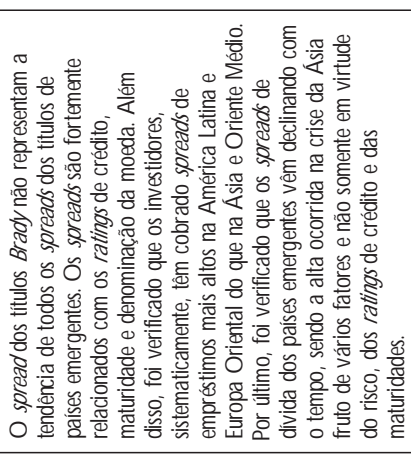 & 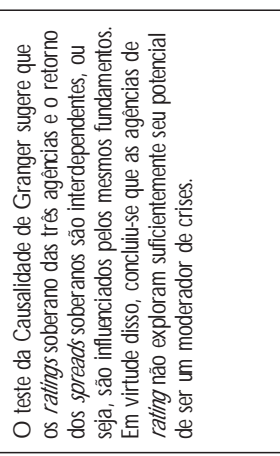 \\
\hline $\begin{array}{l}8 \\
8 \\
8\end{array}$ & 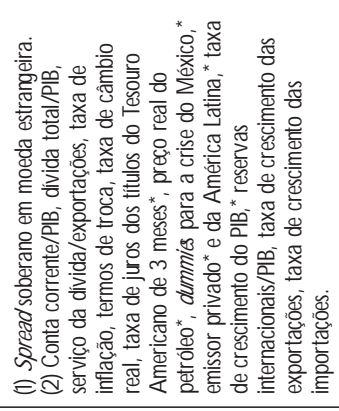 & 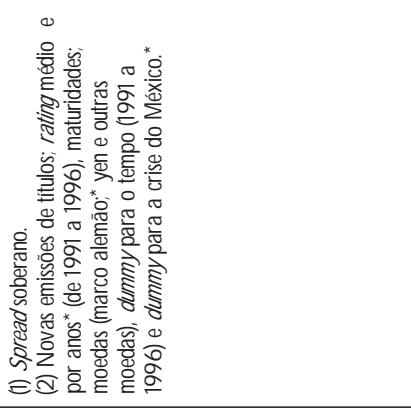 & 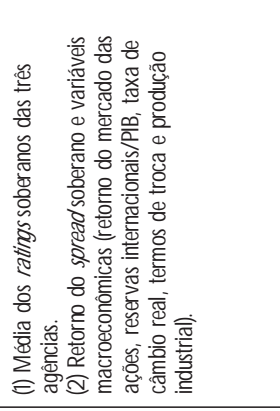 \\
\hline$\frac{8}{2}$ & 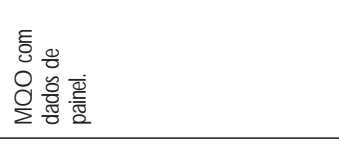 & $\begin{array}{l}0 \\
\dot{\rho} \\
\Sigma\end{array}$ & 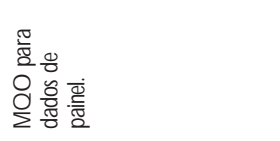 \\
\hline$\frac{f}{1}$ & 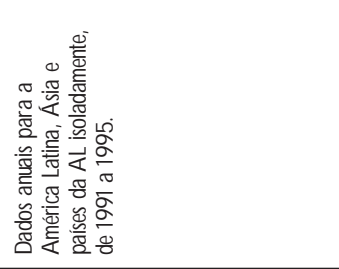 & 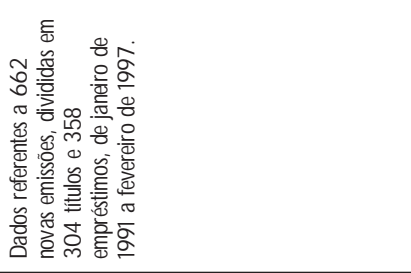 & 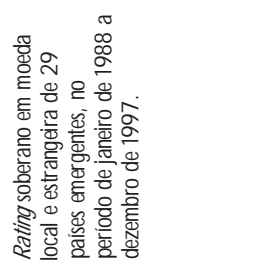 \\
\hline$\frac{\frac{8}{6}}{0}$ & 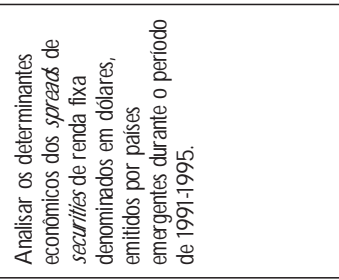 & 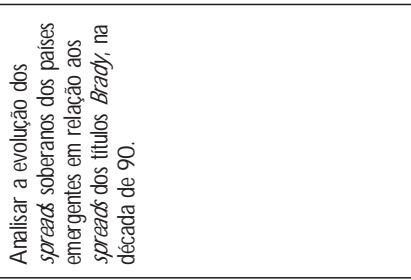 & $\begin{array}{l}r \\
0 \\
8\end{array}$ \\
\hline $\begin{array}{l}\frac{6}{8} \\
\frac{8}{0} \\
\frac{8}{4}\end{array}$ & $\begin{array}{l}\widehat{0} \\
0 \\
\frac{c}{\Sigma} \\
\frac{c}{\Sigma}\end{array}$ & 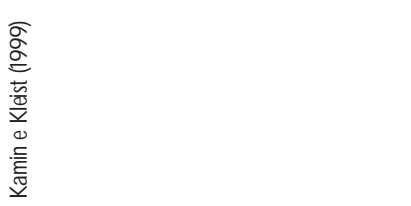 & 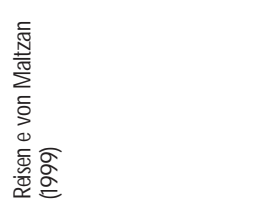 \\
\hline
\end{tabular}

16 Revista A nálise Econômica, Porto A legre, ano 27, n. 51, p. 7-35, março de 2009. 


\begin{tabular}{|c|c|c|}
\hline 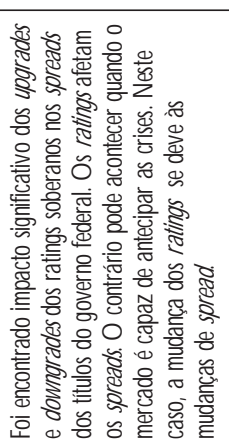 & 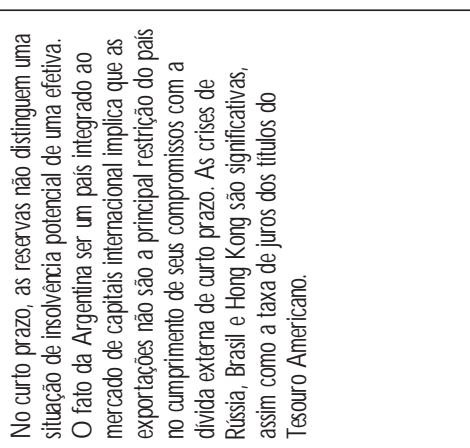 & 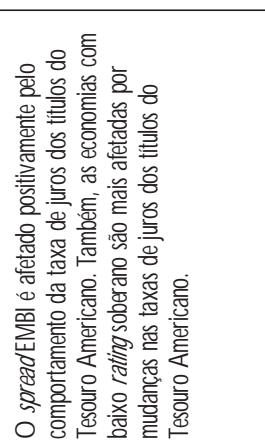 \\
\hline 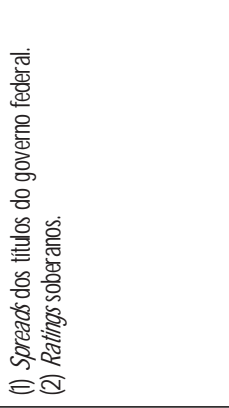 & 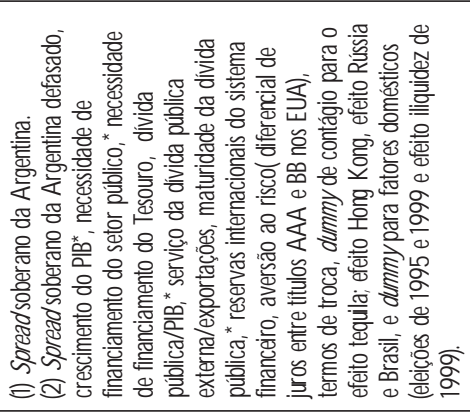 & 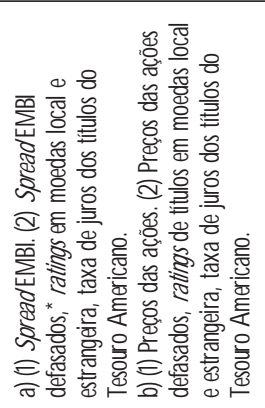 \\
\hline 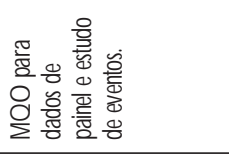 & 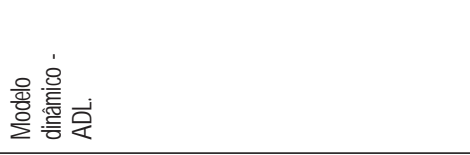 & 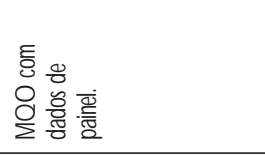 \\
\hline 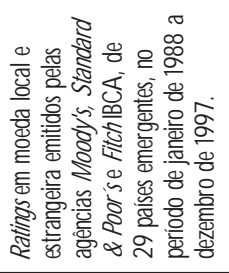 & 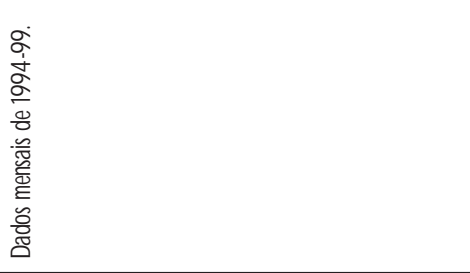 & 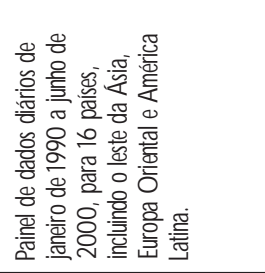 \\
\hline 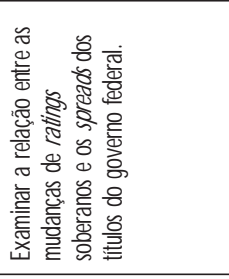 & 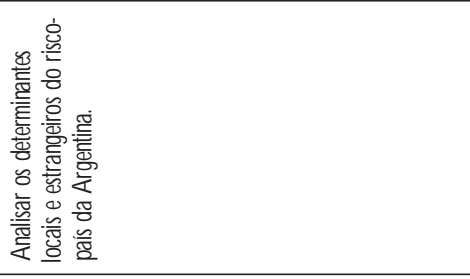 & 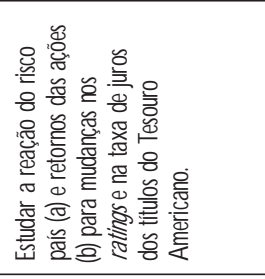 \\
\hline 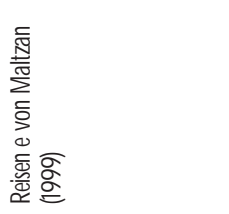 & $\begin{array}{l}\hat{o} \\
o \\
o \\
\frac{0}{\bar{z}} \\
\frac{0}{0} \\
\frac{0}{0}\end{array}$ & 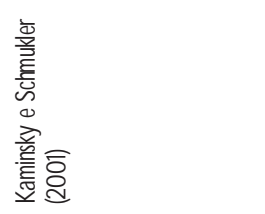 \\
\hline
\end{tabular}

Bone, R. B. A Importância dosfundamentosnos ratingssoberanos brasileiros... 


\begin{tabular}{|c|c|c|c|}
\hline$\frac{6}{8}$ & 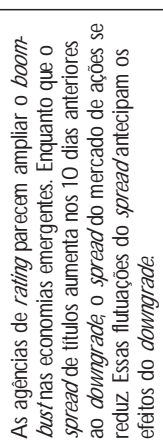 & 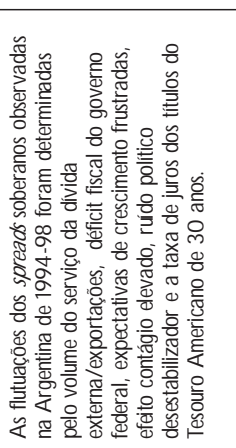 & 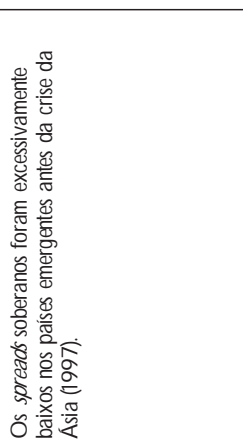 \\
\hline 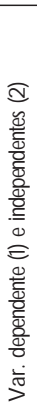 & 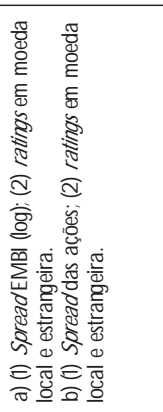 & 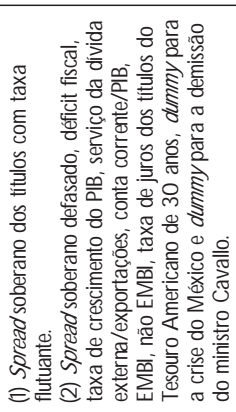 & 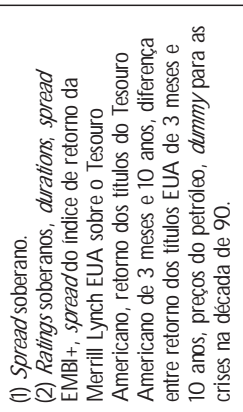 \\
\hline$\frac{8}{\xi}$ & 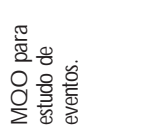 & $\begin{array}{l}\stackrel{0}{o} \\
\frac{\sigma}{\Sigma}\end{array}$ & 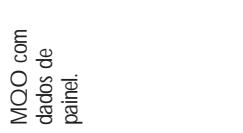 \\
\hline$\frac{8}{g}$ & 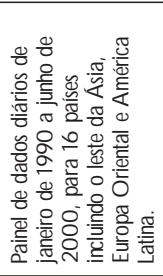 & 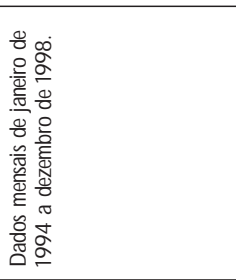 & 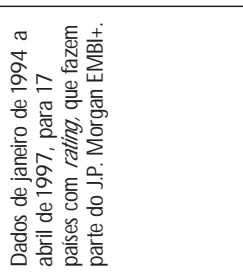 \\
\hline$\frac{8}{0}$ & 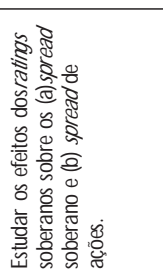 & 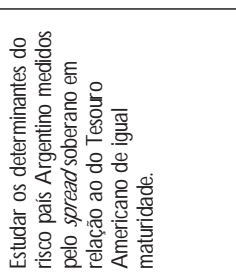 & 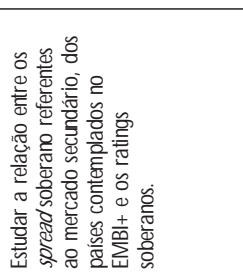 \\
\hline 要 & 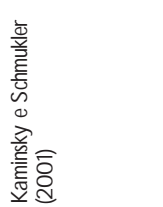 & 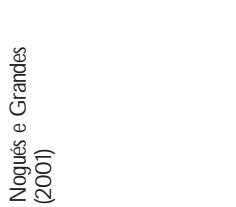 & $\begin{array}{l}\hat{0} \\
0 \\
\hat{d} \\
\hat{n}\end{array}$ \\
\hline
\end{tabular}

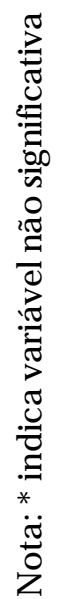




\section{Descrição dos Fundamentos Determinantes dos Ratings Soberanos}

A determinação dos ratings soberanos segue uma metodologia muitas vezes obscura para os analistas de mercado, por que considera fundamentos quantitativos e qualitativos. A pouca clareza se encontra nos fatores políticos - qualitativos - que são de difícil mensuração (HAQUE et al., 1998). Entretanto, o entendimento da importância desses fatores pode dar ao mercado mais uma ferramenta importante no processo de minimização de riscos de default de emissores de títulos.

Os fundamentos contemplados nesta análise são apresentados em séries mensais. ${ }^{6}$ Em virtude disso, sofreram algumas adaptações em relação à metodologia usada pelas agências Standard \& Poor's e Moody's, mas partem do mesmo rigor conceitual. São eles: taxa de crescimento do PIB real, taxa de inflação (IPC), dívida externa sobre as exportações, dívida líquida do setor público total (em \%PIB), transações correntes (em \%PIB) e necessidade de financiamento do setor público (em \%PIB). Por outro lado, desconsideraram-se as variáveis renda per capita, desenvolvimento econômico e história de default. No entendimento das agências, a renda per capita mostra a habilidade do país de pagar as suas dívidas, mas foi retirada de análise por não ter apresentado variação significativa em períodos curtos e ser relevante somente na comparação entre países. Ainda, porque se acredita que a renda per capita possa ser substituída pela taxa de crescimento do PIB real, sem ônus. A exclusão da variável grau de desenvolvimento econômico apresenta dois motivos: primeiro, pela relevância somente entre países e segundo, pelo grau de desenvolvimento do Brasil não ter mudado ao longo do período considerado. A variável história de default também foi excluída, dada a existência de alguns casos no Brasil, mas de períodos anteriores ao estudado neste trabalho. O primeiro default foi em 1983 e se referia à dívida bancária em moeda estrangeira; e os episódios de 1987, 1989 e 1991, respectivamente, relacionavam-se à dívida em moeda local ou à dívida interna (BEERS, 1995 apud CANTOR; PACKER, 1995b). Contudo, são considerados controversos, em virtude dos meios indiretos de calote da dívida. Então, muitos autores consideram a existência de apenas dois defaults no Brasil: em 1930, no governo de Getúlio Vargas, e, em 1987, no de J osé Sarney.

$\mathrm{Na}$ análise do spread soberano, além dos fundamentos, incluiuse a taxa de juros do Tesouro Americano de 3 meses, com a finalidade de verificar sua influência nos fluxos de capitais para o Brasil.

6 Em Cantor; Packer (1996), os fundamentos se apresentam em séries anuais. 
O comportamento de cada fundamento deve seguir a lógica previamente desenvolvida no campo teórico e intuitivo, como pode ser visto do Quadro 3.

Quadro 3 - Comportamento Esperado dos Fundamentos Macroe-conômicos e dosJ uros do Tesouro Americano sobre os Ratings e Spreads Soberanos

\begin{tabular}{|l|c|c|c|}
\hline \multirow{2}{*}{ Fundamentos } & \multirow{2}{*}{ Símbolo } & \multicolumn{2}{c|}{ Sinal da Correlação } \\
\cline { 3 - 4 } & & Rating & Spread \\
\hline Taxa de Crescimento do PIB & PIB & + & - \\
\hline Taxa de Inflação (\%) & IPC & - & + \\
\hline Dívida Externa Líquida do Setor Público (em \% Exportações) & DIV/X & - & + \\
\hline Dívida Líquida do Setor Público Total (em \%PIB) & DLSP/PIB & - & + \\
\hline N ecessidade de Financiamento do Setor Público (em \%PIB) & N FSP/ PIB & - & + \\
\hline Superávit Primário (em \%PIB) & SP/PIB & + & - \\
\hline Transações Correntes (em \% \%IB) & TC/PIB & + & - \\
\hline Dívida Externa Líquida do Setor Público Total (em \% reservas \\
internacionais)
\end{tabular}

Fonte: Elaboração do autor.

Nota: NFSP/PIB é medida com o sinal oposto, uma vez que um superávit é dado por valores negativos.

\section{M etodologia}

A avaliação da importância individual e coletiva dos fundamentos na determinação dos ratings soberanos considera dados mensais de dezembro de 1994 a dezembro de 2002, pelo fato de a primeira emissão de rating soberano - em moeda estrangeira de longo prazo ter ocorrido em dezembro de 1994 (STANDARD; POOR'S, 2003). Contudo, o segundo modelo, que se refere à relação entre o spread soberano, o rating soberano e os fundamentos, contempla um período menor, uma vez que as informações sobre o spread soberano brasileiro iniciaram somente em dezembro de 1995 (MECON, 2003). 
0 rating segue uma classificação ordinal, como pode ser visto na Tabela 1, daí a necessidade de sua transformação em números. A metodologia seguida é similar a de Mulder e Perelli (2001), Reinhart (2001) e de Bloomberg L.P.(2003).

$O$ ordenamento dos ratings soberanos, conforme as escalas da Standard \& Poor's, obedeceu a uma ordinalidade decrescente, uma vez que se acredita que a nota AAA, por possuírem maiores peso/ importância que a nota $D$, deve ter o maior número. Esse entendimento é também seguido por Reinhart (2001, p.10). Além dessa transformação inicial, foram considerados, também, como mudança de rating, os outlooks estável, negativo e positivo, conforme apresentado por Mulder e Perelli (2001, p.6). Esses outlooks, por sua vez, tiveram a seguinte consideração: quando o outlook é positivo, acrescenta-se mais 0,33 na nota inicial, quando ele é negativo, diminuise 0,33 e quando é estável, soma-se zero. Assim, a variedade de notas foi aumentada e, com isso, abrangeu-se a totalidade das mudanças ocorridas nos ratings de um título (neste caso, emitido em moeda estrangeira de longo prazo).

Tabela 1 - Ordenamento dos ratings de crédito Escalas utilizadas pela Standard \& Poor's

\begin{tabular}{|c|c|c|c|}
\hline & 0 rdem & Escala & Interpretação \\
\hline \multirow{10}{*}{ 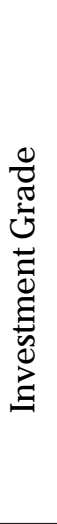 } & 22 & AAA & A ltíssima qualidade \\
\hline & 21 & $A A+$ & \multirow{3}{*}{ A lta qualidade } \\
\hline & 20 & $\mathrm{AA}$ & \\
\hline & 19 & $A A$ - & \\
\hline & 18 & $A+$ & \multirow{3}{*}{ Forte capacidade de pagamento } \\
\hline & 17 & A & \\
\hline & 16 & A. & \\
\hline & 15 & $\mathrm{BBB}+$ & \multirow{3}{*}{$\begin{array}{c}\text { Capacidade de pagamento } \\
\text { adequada }\end{array}$} \\
\hline & 14 & $\mathrm{BBB}+$ & \\
\hline & 13 & BBB- & \\
\hline \multirow{6}{*}{$\begin{array}{l}\frac{0}{0} \\
\frac{0}{0} \\
0 \\
0 \\
\frac{\pi}{\pi} \\
\frac{\pi}{2} \\
\frac{0}{n}\end{array}$} & 12 & $\mathrm{BB}+$ & \multirow{2}{*}{$\begin{array}{l}0 \text { brigações } \mathrm{cl} \text { prob. de } \\
\text { pagamento }\end{array}$} \\
\hline & 11 & BB & \\
\hline & 10 & BB- & Incerteza \\
\hline & 09 & $B+$ & \multirow{3}{*}{0 brigações em alto risco } \\
\hline & 08 & B & \\
\hline & 07 & B- & \\
\hline
\end{tabular}




\begin{tabular}{|c|c|c|c|}
\hline$\frac{0}{\frac{0}{0}}$ & $\begin{array}{l}06 \\
05 \\
04\end{array}$ & $\begin{array}{r}\mathrm{CCC}+ \\
\mathrm{CCC} \\
\mathrm{CCC}-\end{array}$ & $\begin{array}{c}\text { Vulnerabilidade corrente } \\
\text { para estar ou entrar em } \\
\text { default }\end{array}$ \\
\hline 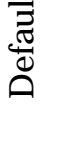 & $\begin{array}{l}03 \\
02 \\
01\end{array}$ & $\begin{array}{r}C C \\
C \\
D\end{array}$ & Falência ou default \\
\hline
\end{tabular}

Fonte: Elaboração própria, baseada em Standard \& Poor's (2003).

A Tabela 2 mostra os ratings soberanos e outlooks emitidos pela Standard \& Poor's para os títulos brasileiros em moeda local e estrangeira de curto e longo prazos. Pode-se verificar que o rating soberano para os títulos em moeda estrangeira de longo prazo foi o primeiro a ser emitido pela agência, por isso foi o escolhido para as análises que se seguem.

Tabela 2 - Ratings Soberanos Brasileiros, 1994-2002

\begin{tabular}{|c|c|c|c|c|c|c|}
\hline \multirow[b]{2}{*}{ Período } & \multicolumn{3}{|c|}{ Moeda Doméstica } & \multicolumn{3}{|c|}{ M oeda Estrangeira } \\
\hline & Credit Watch & $\begin{array}{l}\text { Longo } \\
\text { Prazo }\end{array}$ & O utlook & Credit Watch & $\begin{array}{l}\text { Longo } \\
\text { Prazo }\end{array}$ & O utlook \\
\hline $01-12-94$ & & & & start & $B$ & Positivo \\
\hline 18.07 .95 & & & & upgrade & $B+$ & Estável \\
\hline $20-12-95$ & & & & upgrade & $B+$ & Positivo \\
\hline $19-06-96$ & start & BB & Positivo & confirmado & $B+$ & Positivo \\
\hline $02.04-97$ & upgrade & $B B+$ & Estável & upgrade & BB- & Estável \\
\hline $10-09-98$ & downgrade & $B B+$ & N egativo & downgrade & BB- & N egativo \\
\hline $14-01-99$ & downgrade & BB- & N egativo & downgrade & $B+$ & $N$ egativo \\
\hline $09-11-99$ & upgrade & BB- & Estável & upgrade & $\mathrm{B}+$ & Estável \\
\hline $29.02-00$ & upgrade & BB & Positivo & upgrade & $B+$ & Positivo \\
\hline $03-01-01$ & upgrade & $\mathrm{BB}+$ & Estável & upgrade & BB- & Estável \\
\hline 09.08 .01 & downgrade & $B B+$ & N egativo & downgrade & BB- & $N$ egativo \\
\hline $02-07-02$ & downgrade & BB & Negativo & downgrade & $B+$ & N egativo \\
\hline
\end{tabular}

Fonte: Elaboração do autor, baseada em Standard \& Poor's (2003). 


\subsection{Detalhamento do método M L - 0 rdered Logit 7}

Um modelo ordered tem como principal característica a existência de uma variável dependente ordinal discreta. Por esse motivo, a não cardinalidade e não continuidade dessa variável impossibilita estimar os parâmetros do modelo usando o método de Mínimos Quadrados Ordinários - MQO. Como a ordinalidade, na maioria das vezes, não exige intervalos simétricos, o valor atribuído a um rating investment grade não é o dobro de um rating speculative grade, por exemplo. Em outras palavras, uma nota AAA (de número = 22 ) não é igual a duas notas BB $(=11)$, embora a escala numérica dos ratings possa sugerir esse entendimento.

Nos modelos de variáveis dependentes ordenadas, a observação y denota os resultados representando ratings ordenados. Então, pode-se modelar os ratings considerando uma variável latente $\mathrm{y}_{\mathrm{i}}{ }^{*}$, que depende linearmente das variáveis explicativas $\mathrm{x}$ :

$$
y_{i}^{*}=x_{i}^{`} \beta+\varepsilon_{i}
$$

onde: $\varepsilon$ é uma variável aleatória. A estimativa segue os pressupostos sobre distribuição de erros $\varepsilon_{\mathrm{i}}$.

Os ratings observados sã̃o baseados na variável latente $\mathrm{y}_{i}^{*}$, de acordo com a seguinte regra:

$$
\begin{array}{lll}
y_{i}=0 & \text { se } & y_{i}{ }^{*} \leq \gamma_{1} \\
y_{i}=1 & \text { se } & \gamma_{1}<y_{i}{ }^{*} \leq \gamma_{2} \\
y_{i}=2 & \text { se } & \gamma_{2}<y_{i}{ }^{*} \leq \gamma_{3} \\
\ldots & \ldots & \ldots \\
y_{i}=M & \text { se } & \gamma_{M}<y_{i}^{*}
\end{array}
$$

Salienta-se que os valores escolhidos para representar os ratings em y são completamente arbitrários. 0 modelo requer que valores grandes de ratings correspondam a valores grandes da variável latente, tal que $\mathrm{y}_{\mathrm{i}}^{*}<\mathrm{y}_{\mathrm{j}}^{*}$ implicando $\mathrm{y}_{\mathrm{i}}<\mathrm{y}_{\mathrm{j}}$. Nesse caso, $\mathrm{y}_{\mathrm{i}}^{*}$ seria uma escala numérica não observada, que, posteriormente, é transformada em letras $\left(\mathrm{y}_{\mathrm{i}}\right)$ pelas empresas de rating.

\footnotetext{
7 Esta seção baseia-se em Greene (2000, cap.19) e Eviews (1998).
} 
As probabilidades de cada valor observado de y são dadas por:

$$
\begin{gathered}
\operatorname{Pr}(y=0 / x, \beta, \gamma)=F\left(\gamma_{1}-x^{\prime} \beta\right) \\
\operatorname{Pr}\left(y_{i}=1 / x_{i}, \beta, \gamma\right)=F\left(\gamma_{2}-x_{i}^{\prime} \beta\right)-F\left(\gamma_{1}-x_{i}^{\prime} \beta\right) \\
\operatorname{Pr}\left(y_{i}=2 / x_{i}, \beta, \gamma\right)=F\left(\gamma_{3}-x_{i}^{\prime} \beta\right)-F\left(\gamma_{2}-x_{i}^{\prime} \beta\right) \\
\quad \ldots \\
\operatorname{Pr}\left(y_{i}=M / x_{i}, \beta, \gamma\right)=1-F\left(\gamma_{M}-x_{i}^{\prime} \beta\right)
\end{gathered}
$$

onde $F$ é a função distribuição cumulativa de $\varepsilon$. Há várias opções na literatura para a escolha de $\mathrm{F}$. As mais comuns são a distribuição normal e a logística. Para a logística, a probabilidade é dada por:

$$
\operatorname{Pr}(y=0 / x, \beta, \gamma)=e^{z} /\left(1+e^{z}\right),
$$

onde $z=\gamma_{i}-x^{\prime} \beta$. A estimação é feita pelo método de Máxima Verossimilhança.

A interpretação dos parâmetros requer alguns cuidados, principalmente em relação aos coeficientes estimados. Como os coeficientes estimados não representam o efeito marginal da variável explicativa sobre a variável dependente, é necessário calcular os efeitos marginais para cada um. Seguindo o exemplo de Greene (2000, p. 877), considere que existem $M=3$ categorias. $N$ esse caso, os efeitos marginais correspondentes são:

$$
\begin{aligned}
& \partial \operatorname{Pr}(\mathrm{y}=0) / \partial \mathrm{x}=-\mathrm{f}\left(\gamma_{1}-\mathrm{x}^{\prime} \beta\right) \beta \\
& \partial \operatorname{Pr}(\mathrm{y}=1) / \partial \mathrm{x}=\left[\mathrm{f}\left(\gamma_{1}-\mathrm{x}^{\prime} \beta\right)-\mathrm{f}\left(\gamma_{2}-\mathrm{x}^{\prime} \beta\right)\right] \beta \\
& \partial \operatorname{Pr}(\mathrm{y}=2) / \partial \mathrm{x}=\mathrm{f}\left(\gamma_{2}-\mathrm{x}^{\prime} \beta\right) \beta
\end{aligned}
$$

Para uma mudança de $x_{i}$, o sinal de $\beta$ mostra a direção que essa mudança irá causar na probabilidade de y cair nos extremos do ranking, ou seja, $y=0$ ou $y=2$. Como se pode verificar, o sinal negativo da $\partial \operatorname{Pr}(\mathrm{y}=0) / \partial \mathrm{x}$ faz com que as mudanças se deem na direção oposta de $\beta$ para $\operatorname{Pr}(y=0)$. Já a $\operatorname{Pr}(y=2)$, muda na mesma direção de $\beta$, em virtude do sinal positivo. Por fim, o efeito da probabilidade de cair no ranking intermediário é dado por:

$$
\partial \operatorname{Pr}(y=1) / \partial x=\left[f\left(\gamma_{1}-x_{i}^{\prime} \beta\right)-f\left(\gamma_{2}-x_{i}^{\prime} \beta\right)\right] \beta
$$

Nesse caso, como não se sabe se $f\left(\gamma_{1}-x_{i}^{\prime} \beta\right)$ é maior ou menor que $\mathrm{f}\left(\gamma_{2}-\mathrm{x}^{\prime} \beta\right)$, torna-se impossível determinar, a priori, o sinal desse efeito. 


\section{A nálise dos Resultados}

Os resultados apresentados para a relação entre os ratings soberanos e os fundamentos a seguir baseiam-se na distribuição logística, ou seja, na estimação usando o método ordered logit. 0 estimador ordered logit gerou estimativas com menos erros de previsão que a baseada em ordered probit. Apesar disso, é importante salientar que nessa amostra a escolha do método de estimação ordered logit não afetou as conclusões, pois a significância e os sinais dos coeficientes foram iguais aos encontrados pelo método ordered probit.

Já o confronto entre o rating soberano, o spread Brasil e os fundamentos se baseia no método de Mínimos Quadrados Ordinários, amplamente conhecido na literatura, pois o spread é uma variável contínua e cardinal.

\subsection{A nálise dos ratings soberanos contra os fundamentos}

Com o objetivo de identificar quais fundamentos determinam os ratings soberanos emitidos pela agência Standard \& Poor's para 0 Brasil, procedeu-se à estimação do modelo usando o método ordered logit e as variáveis explicativas - fundamentos. Considerado o período de dezembro de 1994 a dezembro de 2002, os ratings soberanos foram ordenados obedecendo seis níveis de classificação $(8,33=B$ pos.; $8,67=B+$ neg.; $9,00=B+$ est.; $9,33=B+$ pos.; $9,67=B B-$ neg.; $10,00=$ BB- est.).

Conforme a Tabela 3, pode-se verificar que das seis variáveis explicativas, o PIB (taxa de crescimento do PIB real) e as TC/PIB (transações correntes sobre o PIB) não tiveram o sinal esperado. Como 0 TC/PIB tem saldo negativo no Brasil, na maior parte do período analisado (julho de 1997 a dezembro de 2002), o efeito de um aumento é, na verdade, uma diminuição. Sendo assim, o sinal obtido é correto. Por exemplo, se TC/PIB se reduz de -1 para -2 se espera uma piora do rating.

Considerando as probabilidades dos respectivos coeficientes, dois podem ser excluídos do modelo, dado o baixo poder explicativo: o IPC (taxa de inflação) e o PIB. ${ }^{8} 0$ teste de significância do coeficiente do IPC apresentou probabilidade de $15,71 \%$ e do PIB, de $21,42 \%$. A pesar da TC/PIB não apresentar sinal positivo, como esperado, a

\footnotetext{
8 Os resultados, desconsiderando-se as variáveis PIB (taxa de crescimento do PIB) e IPC (taxa de inflação), encontram-se disponíveis com o autor.
} 
probabilidade de exclusão do coeficiente foi de $0 \%$. A estatística LR (com 6 graus de liberdade) registrou valor calculado de 118.12 e probabilidade de $0 \%$, o que permite afirmar que os coeficientes, conjuntamente, possuem poder explicativo sobre a variável dependente ordenada.

Tabela 3 - Variável Dependente Ordenada - Método Logit-: Rating Soberano

\begin{tabular}{|c|c|c|c|c|}
\hline Variáveis Explicativas & Coeficiente & Desvio Padrão & Estatística z & Probabilidades \\
\hline DIV / X & -0.789259 & 0.125487 & -6.289587 & 0.0000 \\
\hline DLSP/ PIB & -0.138342 & 0.051043 & -2.710288 & 0.0067 \\
\hline IPC & -0.495859 & 0.350458 & -1.414889 & 0.1571 \\
\hline N FSP/PIB & -0.732654 & 0.231063 & -3.170797 & 0.0015 \\
\hline $\mathrm{PIB}$ & -0.078958 & 0.063562 & -1.242216 & 0.2142 \\
\hline \multirow[t]{2}{*}{$\mathrm{TC} / \mathrm{PIB}$} & -0.133785 & 0.025552 & -5.235780 & 0.0000 \\
\hline & \multicolumn{3}{|c|}{ Pontos Limítrofes $(y)$} & \\
\hline Limite $p / B+$ neg. $=8,67$ & -14.26138 & 2.368380 & -6.021576 & 0.0000 \\
\hline Limite $p / B+$ est. $=9,00$ & -9.699620 & 1.814697 & -5.345037 & 0.0000 \\
\hline Limite $p / B+p o s .=9,33$ & -8.972431 & 1.757209 & -5.106070 & 0.0000 \\
\hline Limite $p / B B$ - neg. $=9,67$ & -7.052087 & 1.700848 & -4.146217 & 0.0000 \\
\hline Limite $p / B B$ - est. $=10,00$ & -5.491552 & 1.643821 & -3.340723 & 0.0008 \\
\hline Log verossimilhança & -104.1872 & \multicolumn{2}{|c|}{ LR indexador (Pseudo-R2) } & 0.361782 \\
\hline LR estatística (6 gl) & 118.1197 & \multicolumn{2}{|c|}{ Prob. (LR estatística) } & 0.000000 \\
\hline Nㅡ O bservações & 97 & \multicolumn{2}{|c|}{$\mathrm{N} \cong$ ratings ordenados } & 6 \\
\hline
\end{tabular}

A Tabela 4 mostra a previsão dos erros em relação aos ratings soberanos. Os erros de previsão mais significativos se concentram nos ratings $B+$ estável $(9,00), B+$ positivo $(9,33)$ e BB- negativo $(9,67)$. Com relação a $B+$ positivo, pode-se verificar que os fundamentos não permitiram que esse rating fosse previsto corretamente para 0 período em que estava em vigor, de dezembro de 1995 a abril de 1997, e, de fevereiro de 2000 a janeiro de 2001.

De um total de 36 erros de previsão, $88 \%$ dos erros se concentraram nas categorias intermediárias. Em função disso, pode-se afirmar que o comportamento dos fundamentos não foi o único fator determinante desses ratings soberanos. 
Tabela 4 - Previsão da Variável Dependente - Rantings Soberanos

\begin{tabular}{l|c|c|c}
\hline $\begin{array}{c}\text { Ratings com } \\
\text { outlook }\end{array}$ & $\begin{array}{c}\text { Freqüência } \\
\text { observada }\end{array}$ & $\begin{array}{c}\text { Freqüência } \\
\text { calculada }\end{array}$ & $\begin{array}{c}\text { Erro de } \\
\text { Previsão }\end{array}$ \\
\hline B positivo & 7 & 7 & 0 \\
\hline B+ negativo & 16 & 15 & 1 \\
\hline B+ estável & 8 & 0 & 8 \\
\hline B+ positivo & 27 & 42 & -15 \\
\hline BB- negativo & 15 & 6 & 9 \\
\hline BB- estável & 24 & 27 & -3 \\
\hline
\end{tabular}

Para se obter o efeito do comportamento dos fundamentos sobre as probabilidades de ocorrência dos ratings, calculou-se, ceteris paribus, os efeitos marginais no Gráfico 1 . Os dados permitem verificar qual é a mudança na probabilidade de ocorrência em pontos percentuais ( $p p$ ) de cada rating, quando os fundamentos individualmente mudam seu valor em uma unidade.

Analisando a primeira variável, DIV/X (dívida externa sobre as exportações), verifica-se que o aumento em uma unidade fez com que aumentasse a probabilidade de ocorrência do rating $B+$ negativo (10,29 pp) e diminuísse as dos ratings BB- negativo (-10,35 pp) e BB- estável (-5,41 pp).

As mudanças na variável DLSP/PIB (dívida líquida do setor público sobre o PIB), por sua vez, repercutiram muito pouco sobre as probabilidades de ocorrência dos ratings. Acredita-se que a baixa influência se deveu à sua recente inclusão nos comentários realizados pelas agências e nas considerações sobre a saúde do governo. As maiores probabilidades se encontraram nos ratings $B B$ - negativo e $\mathrm{B}+$ negativo: o primeiro, com $-1,81 \mathrm{pp}$ e 0 segundo, com $1,80 \mathrm{pp}$. Ou seja, quando a DLSP/PIB sobe aumentam as possibilidades de ocorrência de $B+$ negativo e diminuem as de BB- negativo.

A NFSP/PIB (necessidade de financiamento do setor público sobre o PIB), quando registrou um aumento em uma unidade, surtiu efeitos marginais positivos nas probabilidades de ratings $B+$ negativo e B+ estável e efeitos negativos em BB- negativo e BB- estável. Portanto, o aumento da NFSP/PIB reduziu a probabilidade de ocorrência de ratings mais altos em favor dos mais baixos.

As transações correntes sobre o PIB (TC/PIB), conforme salientado anteriormente, têm a particularidade de ter saldo negativo em quase a totalidade do período, por isso merece atenção especial. 
Então, quando as TC/PIB diminuem, é por que o saldo das TC se tornou menos problemático, logo, a probabilidade de ocorrência de ratings mais altos é maior ( $\mathrm{B}+$ positivo; $\mathrm{BB}$ - negativo; BB- estável).

Gráfico 1 - Probabilidade de Ocorrência de Ratings Soberanos com mudanças nas variáveis explicativas, 1995-2002

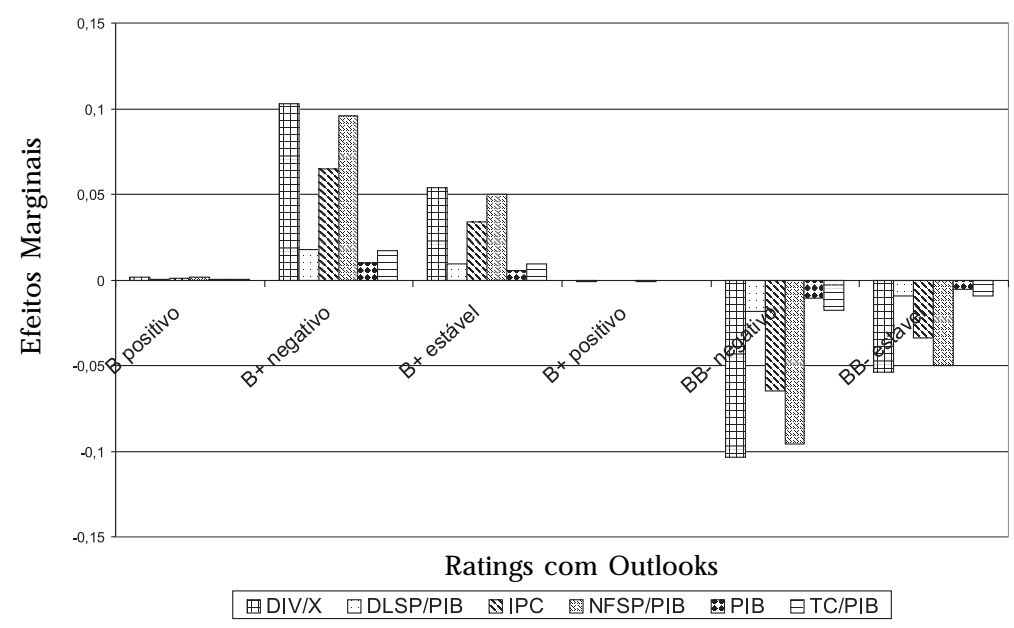

Fonte: Elaboração do Autor.

O Gráfico 2 confronta os ratings soberanos observados e os previstos pelo método ordered logit. ${ }^{9}$ Observando o período de dezembro de 1994 a dezembro de 2002, verifica-se que, em vários momentos a diferença entre os ratings foi nula.

No último trimestre de 1998, o rating previsto sofreu um rebaixamento mais acentuado que o observado, podendo ser função de uma possível antecipação da crise, que ocorreria em janeiro de 1999. As sucessivas diferenças entre o observado e o previsto ocorreram durante o segundo semestre de 1999 e primeiro trimestre de 2000. As diferenças se deram em virtude da permanência de um rating $\mathrm{B}+$ com outlook negativo, de janeiro a novembro, apesar do ajuste dos fundamentos a um nível próximo ao anterior à mudança cambial. Em outras palavras, as agências de rating não alteraram a nota do Brasil quando ela poderia ter sido revista, já no final do primeiro semestre de 1999.

9 O Gráfico 2 mostra os ratings soberanos previstos pelo método de Mínimos Quadrados Ordinários (OLS). Pode-se perceber que as diferenças entre o previsto e o observado são maiores no Método MQO que pelo Método ordered logit. 
No último trimestre de 2001, novas diferenças podem ser identificadas entre 0 rating observado e previsto. Enquanto os fundamentos mantiveram o rating por mais tempo na nota BB- com outlook estável, a agência Standard \& Poor's, em agosto de 2001, rebaixou o outlook para negativo. A pós essa data, o rating previsto foi inferior ao observado até julho de 2002, quando a agência rebaixou novamente o rating soberano de BB- com outlook negativo para B+ com outlook negativo. Esse último rebaixamento proporcionou a igualdade entre os ratings previsto e observado.

Essa comparação permite afirmar que a agência de rating possui postura conservadora, ou seja, não altera as notas em função de pequenas variações dos fundamentos brasileiros - conclusão apontada também por Monfort e Mulder (2000) e Ferri, Liu e Stiglitz (1999) - para o caso da crise da Ásia, e somente emite um upgrade ou downgrade quando os fundamentos sinalizam, por vários meses, uma mudança comportamental positiva ou negativa, respectivamente.

Grafico 2 - Comportamento do rating soberano observado e previsto, 1994-2002:

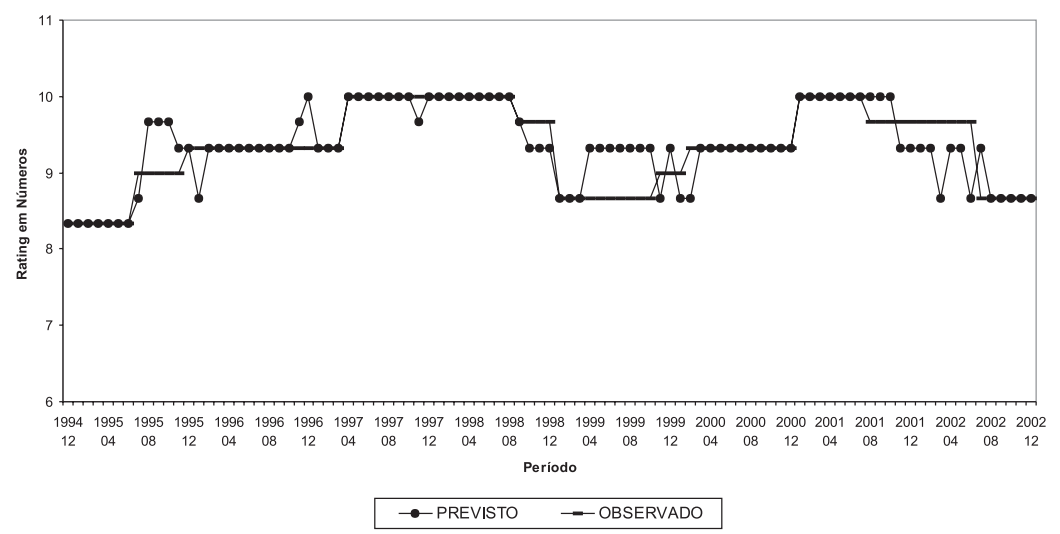

Fonte: Elaboração do autor.

\subsection{A nálise do spread Brasil, do rating soberano e dos fundamentos}

As análises referentes ao spread soberano se devem ao forte conteúdo informacional incluso no seu comportamento. Além do rating e fundamentos, pode carregar outras informações relevantes, que têm o poder de mudar o ânimo do mercado repentinamente.

Para verificar a importância de mudanças do rating soberano e dos fundamentos sobre o spread Brasil, usou-se a metodologia 
sugerida por Cantor e Packer (1996, p. 43). Em outras palavras, buscou-se analisar qual a contribuição informacional do rating soberano, além das provenientes dos fundamentos.

Num primeiro momento, procedeu-se à estimação do spread Brasil (em $\mathrm{ln})^{10}$ em relação ao rating soberano (equação1). Os resultados foram conforme o esperado, ou seja, o spread Brasil tende a cair quando o rating soberano aumenta e vice-versa. O coeficiente angular é significativo, assim como o teste $F$, apesar do $R^{2}$ ajustado ser relativamente baixo, 32,3\%. Contudo, pode-se afirmar que o rating soberano possui apenas parte das informações contidas no spread Brasil.

A equação 2 apresenta o spread Brasil em função dos fundamentos. Todos os sinais foram conforme o esperado, com exceção do TC/PIB e dos JUROS EUA. Como salientou-se anteriormente, 0 saldo negativo das transações correntes brasileiras faz com que um aumento seja encarado como uma melhora, embora represente uma piora. Então, o sinal positivo do coeficiente TC/PIB é devido ao aumento do saldo negativo, o que leva a um maior spread Brasil. Por outro lado, os JUROS EUA deveriam apresentar sinal positivo em relação ao spread Brasil, dado que um aumento dos juros repercute, na maioria dos países emergentes, num aumento do spread soberano (KAMINSKY; SCHMUKLER, 2001, p. 6). No caso brasileiro, essa relação é inversa, além do baixo poder explicativo dessa variável sobre o spread Brasil. As variáveis significativas da equação 2 são: NFSP/ $\mathrm{PIB}, \mathrm{DLSP} / \mathrm{PIB}$ e TC/PIB. Com a significância do teste $\mathrm{F}$ e com $0 \mathrm{R}^{2}$ ajustado de $68,4 \%$, o poder explicativo da equação 2 é maior que 0 da equação 1 , o que permite afirmar que as variáveis acima listadas possuem maior poder informacional em relação ao spread Brasil do que 0 rating soberano. Isto é, há perda informacional quando se usa rating ao invés de fundamentos.

Tabela 5 - Importância dos Ratings Soberanos e Fundamentos Variável Dependente: Log (spread Brasil)

\begin{tabular}{c|c|c|c|c|c}
\hline Variáveis Explicativas & (equação 1) & (equação 2) & (equação 3) & (equação 4) & (equação 5) \\
\hline \multirow{2}{*}{ Constante } & $11.201^{*}$ & $4.836^{*}$ & $6.664^{*}$ & $5.403^{*}$ & $6.292^{*}$ \\
& $(9.617)$ & $(8.917)$ & $(3.906)$ & $(4.189)$ & $(5.508)$ \\
\hline \multirow{2}{*}{ Rating } & $-0.480 *$ & & -0.145 & -0.0804 & -0.159 \\
& $(-3.897)$ & & $(-1.209)$ & $(-0.791)$ & $(-1.861)$ \\
\hline \multirow{2}{*}{ DIV /X } & & 0.035 & 0.021 & 0.022 & \\
& & $(1.937)$ & $(0.983)$ & $(1.068)$ & \\
\hline
\end{tabular}

10 Para essa estimativa, também obteve-se os resultados com o spread em pontos base. Os sinais dos coeficientes, a significância dos respectivos testes $t$, o $R^{2}$ ajustado e a estatística $F$ levaram às mesmas conclusões. 


\begin{tabular}{|c|c|c|c|c|c|}
\hline PIB & & $\begin{array}{l}-0.004 \\
(-0.478)\end{array}$ & $\begin{array}{l}-0.005 \\
(-0,741)\end{array}$ & $\begin{array}{l}-0.005 \\
(-0.643)\end{array}$ & \\
\hline N FSP/PIB & & $\begin{array}{l}0.167^{*} \\
(4.113) \\
\end{array}$ & $\begin{array}{l}0.132 * \\
(2,145) \\
\end{array}$ & $\begin{array}{l}0.164^{*} \\
(3.315) \\
\end{array}$ & $\begin{array}{l}0.144^{*} \\
(3.011)\end{array}$ \\
\hline DLSP/PIB & & $\begin{array}{c}0.0522 * \\
(4.216)\end{array}$ & $\begin{array}{c}0.0428^{*} \\
(2,632)\end{array}$ & $\begin{array}{l}0.056 * \\
(4.975)\end{array}$ & $\begin{array}{r}0.054^{*} \\
(4.711)\end{array}$ \\
\hline$T C / P I B$ & & $\begin{array}{l}0.010 * \\
(3.351)\end{array}$ & $\begin{array}{l}0.006 \\
(1.809)\end{array}$ & $\begin{array}{l}0.009 * \\
(2.639)\end{array}$ & $\begin{array}{l}0.006 * \\
(3.902)\end{array}$ \\
\hline$I P C$ & & $\begin{array}{l}0.080 \\
(1.755)\end{array}$ & $\begin{array}{l}0.056 \\
(1.421)\end{array}$ & $\begin{array}{l}0.085^{*} \\
(2.234)\end{array}$ & $\begin{array}{l}0.092 * \\
(2.616)\end{array}$ \\
\hline JUROS EUA & & $\begin{array}{l}-3367 \\
(-0.827)\end{array}$ & $\begin{array}{r}-5.261 \\
(-1.398) \\
\end{array}$ & & \\
\hline $\mathrm{R}^{2}$ ajustado & 0.323 & 0.684 & 0.691 & 0.681 & 0.675 \\
\hline Desvio Padrão & 0.324 & 0.221 & 0.219 & 0.222 & 0.225 \\
\hline Estatística F & 41.029 & 26.999 & 24.520 & 26.67 & 35.924 \\
\hline Prob.(F-estatístico) & 0.000 & 0.000 & 0.000 & 0.000 & 0.000 \\
\hline $\mathrm{N} \cong$ observações & 85 & 85 & 85 & 85 & 85 \\
\hline
\end{tabular}

Fonte: Elaboração do autor, baseado em Sandard \& Poor's(2003); BCB (2003); I lpeadata (2003).

Nota: correção pelo Desvio Padrão Newey-West HAC.

* Significante ao nível de $5 \%$.

A equação 3 contempla os fundamentos, mais os J UROS EUA e o rating soberano como variáveis explicativas do comportamento do spread Brasil. Os sinais dos coeficientes foram conforme o esperado, com exceção das TC/PIB e J UROS EUA. Nessa equação, com o R ${ }^{2}$ ajustado de $69,1 \%$ e o teste $F$, com probabilidade de $0,00 \%$, as únicas variáveis significativas foram: NFSP/PIB e DLSP/PIB. Acredita-se que algumas variáveis contemplam informações contidas em outras variáveis - multicolinearidade, repercutindo na aceitação da hipótese nula $\left(\mathrm{H}_{0}: \beta_{\mathrm{i}}=0\right)$ quando ela é falsa (erro do tipo II). Mais especificamente, o PIB, IPC e DIV/X continuam a manter a mesma tendência da equação 2, ou seja, de não terem papel importante na determinação do spread Brasil. Em relação ao rating soberano, sua baixa representatividade é por que não adiciona nenhuma informação além das contidas na NFSP/PIB e DLSP/PIB. Com isso, é possível afirmar que o rating soberano, no caso brasileiro, pode ser excluído quando se procura identificar os fundamentos que alteram o humor do mercado em relação aos títulos soberanos brasileiros. 
Na equação 4, seguiu-se a sugestão de Cantor e Packer (1996), contemplando os fundamentos e desconsiderando os J UROS EUA. Nesse caso, as variáveis significativas são: NFSP/PIB, DLSP/PIB, TC/ PIB e IPC. As variáveis PIB e DIV/X, mais uma vez, não foram significativas. Por outro lado, o IPC, que não se mostrava representativo nas equações 2 e 3, passou a ser com a retirada dos J UROS EUA. O $R^{2}$ ajustado registrou $68,1 \%$ e a estatística $F$ 26,67 com probabilidade de 0,00\%.

Por fim, a equação 5 apresentou as seguintes variáveis significativas: NFSP/PIB, DLSP/PIB, TC/PIB e IPC. O rating, apesar de não ter um teste $t$ favorável, registrou seu maior coeficiente e respectivo teste t. Isso leva a concluir que a retirada das variáveis DIV/X e PIB deram ao rating um maior poder explicativo em relação ao spread Brasil. O $\mathrm{R}^{2}$ ajustado foi de $67,5 \%$ e a estatística $F$ de 35,92 , com probabilidade de $0,00 \%$.

$\mathrm{Na}$ Tabela 5 , procurou-se verificar a capacidade explicativa do rating soberano, dos fundamentos e dos J UROS EUA sobre o spread Brasil. Em nenhum dos casos, o rating soberano foi significativo bem como a DIV/X, o PIB e os JUROS EUA. Quanto ao IPC e TC/PIB, ambos alteraram o poder explicativo em relação ao spread Brasil quando se mudou a especificação dos modelos. Com relação a NFSP/ PIB e DLSP/PIB, foram relevantes em todas as especificações.

\section{Considerações Finais}

Após as crises internacionais da década de 90, muitas críticas foram dirigidas às agências de rating, com o propósito de saber quais as verdadeiras variáveis relevantes no processo de classificação. Isso por que esse processo tem sido obscuro para a maioria dos analistas de mercado, pois as mudanças ocorrem muitas vezes atrasadas ou antecipadas, em relação à tendência observada nos fundamentos. Em outras palavras, as agências têm alongado as crises e pouco previsto as mesmas, o que é um sinal de fragilidade informacional.

Nesse sentido, este trabalho buscou verificar a importância dos fundamentos na determinação dos ratings brasileiros para o período de dezembro de 1994 a dezembro de 2002. Além disso, procurou saber qual a influência dos fundamentos, dos ratings e dos juros americanos de curto prazo sobre o comportamento do spread soberano brasileiro.

A estimação da equação referente à importância dos fundamentos sobre os ratings soberanos foi realizada com a aplicação do 
método ordered logit. Esse método foi escolhido por produzir menos erros de previsão que o ordered probit, além de possibilitar a transformação dos ratings em números sem o uso de escalas de notas de modo arbitrário, como exigido pelo Método de MQO.

Os resultados obtidos mostraram que, dos fundamentos escoIhidos, as variáveis DIV/X, DLSP/PIB, NFSP/PIB e TC/PIB foram significativas em relação ao rating soberano brasileiro, com exceção da IPC e PIB. Observando o Gráfico 2, pode-se verificar os períodos em que os erros de previsão foram mais frequentes, o segundo semestre de 1999 até o primeiro semestre de 2000 e o último trimestre de 2001 até o terceiro trimestre de 2002. No primeiro caso, os erros foram originados do conservadorismo das agências em relação aos efeitos da mudança cambial nos fundamentos e o segundo caso, pela manutenção dos fundamentos em níveis pouco satisfatórios e pela grande incerteza política vivida pelo país neste período de pré-eleições presidenciais. Mas, olhando o todo, pode-se dizer que ocorreram muitos acertos. Isso possibilita afirmar que os fundamentos corroboraram com as mudanças de rating soberano, na maioria dos casos, e que o método ordered logit aplicado na variável dependente foi bem sucedido.

A segunda preocupação deste trabalho referiu-se à importância dos fundamentos, dos ratings soberanos e dos juros americanos de curto prazo sobre o comportamento do spread Brasil. O rating soberano foi a única variável de baixa representatividade, pois acredita-se que as demais variáveis já possuem as informações necessárias para explicar o comportamento do spread Brasil.

Esses resultados mostraram que os fundamentos dão uma boa bagagem informacional às agências de rating e aos poupadores em geral, no caso do Brasil, pois os erros de previsão foram baixos, com exceção do período posterior à mudança cambial e anteriores às eleições presidenciais de 2002.

Para explicar o comportamento do spread Brasil, os fundamentos significativos estatisticamente foram NFSP/PIB, DLSP/PIB e IPC, e as informações contidas no rating soberano pouco ajudaram. Cabe salientar, que a relevância das variáveis ligadas à saúde do governo no processo de rating é um indicativo da importância desse setor na captação de recursos externos.

Baseados na amostra escolhida e nos resultados obtidos, podese concluir que as expectativas do mercado quanto à política econômica do país e às mudanças de poder no governo federal exercem forte interferência no processo de rating soberano e no spread Brasil. 


\section{Referências}

AFONSO, ANTÓNIO. Understanding the Determinants of Government Debt Ratings: Evidence for the Two Leading Agencies. CISEP working paper, February 2002. [http: // pascal.iseg.utl.pt/ depteco/wp/wp022002.pdf]

BANK FOR INTERNATIONAL SETTLEMENTS. Long-term rating scales comparison. Basel Committee: Publications, 2001. [www.bis.org/bcbs/qisrating.htm]

BLOOMBERG, L.P., 2003. [www.bloomberg.com]

BROOKS, R. FAFF, R.; HILLIER, D. The national market impact of sovereign rating changes. J ournal of Banking \& Finance, article in press, 2003.

CANTOR, R.; PACKER, F. Determinants and Impact of Sovereign Credit Ratings. Economic Policy Review, v. 2, no 2, O ctober 1996 [www.ny.frb.org/rmaghome/eco_pol/ 1096cant.html]

CANTOR, R.; PACKER, F. Multiple Ratings and Credit Standards: Differences of O pinion in the Credit Rating Industry. Research Paper 9527, December 1995a.

CANTOR, R.; PACKER, F. Sovereign Credit Ratings. Current Issues in Economics and Finance, vol.1, n. 3, J une 1995b.

EICHENGREEN, B.; MODY, A. What Explains Changing Spreads on Emerging-market debt: fundamentos or market sentiment? NBER Working Paper Series, wp 6408, February 1998.

FERRI, G. LIU, L. G.; STIGLITZ, J. E. The procyclical role of rating agencies: evidence from the East Asian crisis. Economic Notes, vol.28, n. 3, 1999.

FMI. Emerging market in the new financial system: nonstandard responses to external pressure and the role of the major credit rating agencies in global financial market. 1999a [www.imf.org/external/pubs/ft/icm/1999/pdf/file05.pdf]

FMI. Credit Ratings and the recent crises. 1999b. [www.imf.org/external/pubs/tt/icm/1999/ pdf/annexV.pdf]

GREENE, W.H. Econometric Analysis. 4a Edition. Prentice-Hall, Inc. N ew J ersey, 2000.

HAQUE, N. MARK, N.; MATHIESON, D. The relative importance of political and economic variable in creditworthiness ratings. FM I: Working Paper. 98/46. A pril 1998.

J .P. MORGAN. Emerging M arkets Bonds Index, September 2001. [www.jpmorgan.com]

KAMIN, S.B.; VON KLEIST, K. The evolution and determinants of emerging market credit spreads in the 1990s. Bis: Working Paper no 68, May 1999.

KAMINSKY, G.; SCHMUKLER, S. Emerging Markets Instability: Do sovereign Ratings Affect Country Risk and Stock Returns? World Bank Policy Research Working Paper, February 2001. [www.worldbank.org/wp/2452_wps2678.pdf]

LARRAÍN, F. REISEN, H.; VON MALTZAN, J. Emerging market risk and sovereign credit ratings. OECD Development Centre: Tecnical Papers no 124, A pril 1997b.

MIN, HON G G. Determinants of Emerging Market Bond Spread: Do Economic Fundamentos Matter? World Bank, Policy Research Paper no 1899, 1998.

MINISTERIO DE LA ECONOMÍA DE LA ARGENTINA - MECON. Informacíon Económica: Mercado de Capitales, fevereiro 2003. [www.mecon.gov.ar]

MONFORT, B.; MULDER, C. Using Credit Rating for Capital Requeriments on Lending to Emerging Market Economies: Possible Impact of a N ew Basel Accord. IM F, W P/00/ 69, March 2000. 
MOODY'S INVESTORS SERVICE. Actuación de Moody's ante situaciones hipotéticas e información confidencial. Resultado Del Comité Permanente Sobre Procesos Y Documentación. Enero 2000a.

July $2000 \bar{b}$.

. Sovereing Debt: What happens if a sovereign defaults? Special Comment.

Off-balance-sheet exponsures: Implications for credit quality of subsovereign governments. Rating M ethodology. J une $2000 \mathrm{~d}$.

July 17,2001 .

Rating List: Government Bonds \& Country Cellings, Global Credit Research.

. Ratings \& ratings actions. [www.Moody's.com/ratings/ratdefs.htm], 1999.

MULDER, C.; PERRELLI, R. Foreign Currency Credit Ratings for Emerging Market Economies. IMF, W P/01/191, November 2001.

NICKELL, P., PERRAUDIN, W.; VAROTTO, S.. Stability of Rating Transitions. Bank of England, Working Paper, December 1998.

NOGUÉS, J .; GRANDES, M. Country Risk: Economic Policy, Contagion effect or Political Noise? J ournal of Applied Economics, vol. IV, no 1, May 2001.

OKS, D. \& PADILLA, H.G.G. Determinantes del riesgo país em Argentina durante 1994-1999. Banco Central De La República Argentina: nota técnica no 11. Octubre 2000. REINHART, CARMEN. Sovereign Credit Ratings Before and After Financial Crises. University of Maryland and NBER. Working Paper, February, 2001.

REISEN, H. \& VON MALTZAN, J. Boom and Bust and Sovereign Ratings. International Finance vol. 2, № :2, 1999.

STANDARD \& POOR'S. Sovereign ratings history since 1975. Commentary. J uly 2001[www.Standard \& Poor's.com/ratings/actions/ratingslists/sovereigns/articles/ sovhis0123.htm],

As respostas políticas do governo são essenciais para os soberanos dos mercados em desenvolvimentos. September 2001. [www.Standard \& Poor's.com/ latinamerica/selcom_WTC_respostas_politicas1.htm]

Global Financial System Stress. 2001. [www.Standard \& Poor's.com/ ratingsdirect/globalfinance/htm]

SY, AMADOU N.R. Emerging market bond spreads and sovereign credit ratings: reconciling market views with economic fundamentals. Emerging Markets Review, vol.3, série 4, p.380-408, 2002.

Recebido em 30/04/2008.

Aceito em 21/05/2008. 
